\title{
Prevalência do herpes-vírus humano tipo 1 em neoplasias cutâneas epiteliais malignas
}

\author{
Prevalence of human herpes virus type 1 in epithelial skin cancer
}

Sylvia Ypiranga ${ }^{1}$

\author{
Aparecida Machado de Moraes $^{2}$
}

\begin{abstract}
Resumo: FundamenTos - O DNA viral pode atuar como oncogene, favorecendo o desenvolvimento de neoplasias, como as linfoides e da pele. Entre esses vírus, encontram-se alguns herpes-vírus humanos.

Овјетіvо - Identificar a presença de DNA do herpes-vírus humano tipo 1 em neoplasias epiteliais pré-malignas, malignas e pele normal de indivíduos controle, avaliando seu papel na carcinogênese.

MÉTODOS - Identificação, por reação em cadeia da polimerase, do DNA viral do tumor e pele sã de 41 pacientes e comparação com grupo controle, sem neoplasia. Análise estatística: Testes de Fisher e de McNemar.

Resultados - O vírus foi identificado em 20 indivíduos sem e em 21 com neoplasia. Destes últimos, 11 o expessaram apenas nas células tumorais. A diferença, entretanto, não foi estatisticamente significante.

CONCLUSÕES - Parece não haver relação direta entre o encontro do DNA viral na pele sã e na pele tumoral. Sua presença pode facilitar o desenvolvimento da neoplasia ou apenas coincidir de se localizar onde esta já ocorreu.

Palavras-chave: Herpes-vírus humano 1; Neoplasias cutâneas; Reação em cadeia de polimerase; Vírus oncogênicos
\end{abstract}

Abstract: Background - Viral DNA may act as an oncogene, especially in skin and lymphoid organs. This group includes some human herpes virus.

Objective - To identify human herpes virus type 1 DNA in pre-malignant and malignant skin samples of epithelial tumors comparing to normal skin to determine its role in carcinogenesis.

Methods - Forty-one patients with epithelial tumors were submitted to biopsies from tumor and normal skin. The control group comprised 41 biopsies from patients with other dermatoses than cancer. After DNA extraction, polymerase chain reaction was performed to identify 199-bp band. The results were statistically evaluated by Fisher and McNemar tests.

Results - The virus was identified in 20 subjects without cancer and in 21 with skin cancer. From these, 11 expressed it only in tumor cells. This difference was not significant.

Conclusion - There seem to be no direct relation between viral findings in normal skin and skin cancer cells. It may act as a promoter or just coexist at the same site where a neoplastic transformation has already occurred.

Keywords: Herpesvirus 1, human; Oncogenic viruses; Polymerase chain reaction; Skin neoplasm

\footnotetext{
Recebido em 29.6.2007.

Aprovado pelo Conselho Consultivo e aceito para publicação em 06.03.09.

* Trabalho realizado na Universidade Estadual de Campinas (Unicamp) - Campinas (SP), Brasil.

Conflito de interesse: Nenhum / Conflict of interest: None

Suporte financeiro: Fundação de Auxilio à Pesquisa - FAEP - Unicamp, Termo 519.294.

Dermatologista. Mestre em clínica médica - Universidade Estadual de Campinas (Unicamp) - Campinas (SP), Brasil.

Dermatologista. Livre-docente em dermatologia - Universidade Estadual de Campinas (Unicamp) - Campinas (SP), Brasil.

(C)2009 by Anais Brasileiros de Dermatologia
} 


\section{INTRODUÇÃO}

Muitos vírus podem participar da carcinogênese e têm sido considerados fatores de risco para o desenvolvimento de neoplasias em diversos órgãos, em especial, os cutâneos e de linhagem linfoide. ${ }^{1-4}$ Além de participar diretamente na carcinogênese, os vírus são importantes modelos e auxiliam a compreensão dos mecanismos de controle do crescimento celular.

Para o desenvolvimento de neoplasias, estão envolvidos múltiplos fatores e, nesse contexto, o DNA viral pode agir como oncogene, por alguns mecanismos: os vírus podem afetar os mecanismos de reparo genético, levando ao aumento na taxa de mutação; as reações inflamatórias secundárias podem induzir a formação da neoplasia; a replicação continuada pode afetar os mecanismos fisiológicos de controle celular e, finalmente, o vírus pode agir diretamente na carcinogênese, como indutor de mutações, desaparecendo após, sem deixar traços. ${ }^{2,5,6}$

É necessário que a infecção viral preceda a neoplasia e se torne latente por um período, para então, determinar a transformação celular e o câncer.

O papilomavírus humano (HPV) tem sido bem estudado, e seu papel na origem do câncer geniturinário e dos tumores cutâneos presentes na epidermodisplasia verruciforme (EV) está bem estabelecido. 5, 7-10

Acredita-se que cerca de $15 \%$ das neoplasias sejam de origem viral. Além do HPV, outros vírus são descritos como oncogenes, como o vírus da hepatite $\mathrm{C}$ e alguns herpes-vírus humanos (HHV).

Os HHV apresentam caracteristicamente ciclos alternados de latência e estado lítico. A relação de alguns deles com neoplasias está bem estabelecida, como no caso de Epstein-Barr vírus (EBV) e HHV tipo 8. ${ }^{13,14}$ Outros HHV já foram relacionados, com significância variável, a determinadas neoplasias (Quadro 1). ${ }^{14,15}$

Ainda que não exista comprovação experimental da oncogenia do HHV tipo 1 (HHV1) na pele, algumas evidências sugerem sua participação em neoplasias cutâneas, atuando como co-carcinógeno na inativação de genes supressores tumorais, interferindo no ciclo celular e nos mecanismos de reparação do DNA. ${ }^{2}$

Alguns autores têm feito descrições clínicas de sua participação em carcinoma bucal, carcinoma cutâneo epidermoide, micose fungoide, carcinoma de cabeça e pescoço e carcinoma de colo de útero. ${ }^{6}$

Este estudo foi desenvolvido no sentido de se verificar a presença do HHV1 na pele de pacientes portadores de tumores cutâneos epiteliais pré-malignos, malignos e pele normal de controle e observar seu impacto junto à patogênese cutânea.

\section{CASUÍSTICA}

Trata-se de estudo prospectivo, não randomizado, descritivo e comparativo.
No grupo de estudo (GE) - chamado de neoplasia cutânea epitelial maligna - foram incluídos 41 pacientes com tumores cutâneos e lesões pré-neoplásicas de origem epitelial, como carcinoma epidermoide (CEC), carcinoma basocelular (CBC) e queratoses actínicas (QA). Desses pacientes, foram colhidas amostras de pele acometida pela doença e de pele sã.

Um grupo controle (GC) foi formado com 41 biópsias de pele de pacientes acometidos por outras dermatoses não neoplásicas, que tivessem sido submetidos a cirurgia dermatológica por qualquer outra razão não neoplásica .

Todos os pacientes assinaram termo de consentimento informado, previamente aprovado pelo Comitê de Ética da Instituição, antes de ingressar no estudo.

Os fragmentos colhidos por biópsia foram congelados e armazenados a $-80^{\circ} \mathrm{C}$ até que fosse realizada a extração de DNA, o que foi feito segundo a técnica da proteinase $\mathrm{K} / \mathrm{fenol} / \mathrm{clorofórmio/etanol,} \mathrm{no}$ Laboratório de Genética Molecular do Câncer, Unicamp.

Para o estudo molecular, foram usados dois primers (Invitrogen Brasil $^{\circledR}$ ):

sense = 5' TGCTCCTACAACAAGTCTCTGGG 3'

antisense = 5' CGGTGCTCCAGGATAAACTGTG 3'

Eles amplificam a glicoproteína $\mathrm{D}(\mathrm{gD})$ do envelope viral do HHV.

Com essa sequência de oligonucleotídeos, foram realizadas reações em cadeia da polimerase (PCR), seguindo a metodologia convencional, no Laboratório de Reumatologia, Unicamp.

Para a PCR ser considerada positiva para o DNA do HHV1, observava-se banda de 199 pares de bases (pB), na presença de controles positivo e negativo.

A análise estatística baseou-se nas diferenças entre a presença ou não do HHV1 nas amostras de DNA colhidas da pele. O teste de Fisher foi aplicado para verificar diferenças na distribuição de uma característica categorizada em função de outra também categorizada. A comparação da positividade entre tecido lesionado e normal foi estabelecida pelo teste de McNemar, para amostras relacionadas.

O nível de significância adotado para os testes estatísticos foi de $5 \%{ }^{17}$

\section{RESULTADOS}

Os resultados foram obtidos a partir de biópsias de 41 pacientes do Serviço de Dermatologia, do Hospital das Clínicas, Unicamp, admitidos no Serviço por demanda espontânea e que, após o diagnóstico, foram conduzidos e tratados da maneira indicada a cada caso.

O GE foi composto por 21 homens e 20 mulheres, com média de idade superior a 51 anos (64\%). 
QUADRo 1: Herpes-vírus que se podem relacionar a determinadas neoplasias

\begin{tabular}{|ll|}
\hline Vírus & Neoplasia relacionada \\
HHV tipo 1 & $\begin{array}{l}\text { Carcinomas de cabeça e pescoço } \\
\text { Carcinoma cervicouterino }\end{array}$ \\
HHV tipo 2 & Carcinoma de colo de útero \\
HHV tipo 4 & $\begin{array}{l}\text { Doença de Hodgkin } \\
\text { Outras doenças linfoproliferativas }\end{array}$ \\
HHV tipo 6 & Linfomas \\
HHV tipo 8 & Sarcoma de Kaposi \\
& Linfomas primários de efusão \\
& Doença de Castleman \\
& Mieloma múltiplo \\
\hline
\end{tabular}

HHV: Herpes-vírus humano

Notou-se marcante predomínio no desenvolvimento das neoplasias epiteliais entre as pessoas de pele clara, em especial os fototipos 1, 2 e 3 da classificação de Fitzpatrick, sobre os demais (87\%).

O GC formou-se a partir de pacientes do mesmo Serviço e do Ambulatório de Dermatologia do Hospital e Maternidade Celso Pierro - Pontifícia Universidade Católica de Campinas e incluía portadores de outras dermatoses. Foi composto por 19 homens e 22 mulheres, com idade entre 18 e 70 anos; a maioria com pele clara (64\%).

O HHV1 foi identificado em 21 pacientes do GE, entre os subgrupos de tumor e de pele sã, e em 20 pacientes do GC.

Visando à comparação entre os grupos de estudo e controle, foram consideradas as amostras de pele normal, comuns a ambos. De tal forma, o HHV1 esteve presente em 10 amostras de pele sã do GE e em 20 do GC, sendo $\mathrm{p}=0,038$ (Tabela 1 ).

No GE, comparando-se a pele acometida pela neoplasia e a pele aparentemente sã, o DNA do HHV 1 foi identificado em 17 das amostras de biópsias de tumor e em 10 biópsias de pele normal, porém sem diferença estatística significativa entre os dois subgrupos (Tabela 2).

Apesar de pouco significante, notou-se maior identificação do HHV 1 (13\%), entre os CECs e QAs, ambos de origem espinhosa, em relação aos CBCs (4\%). Identificou-se ainda um subgrupo não representativo, incluído no GE, de seis indivíduos quimicamente imunossuprimidos, todos transplantados renais. Esses pacientes faziam parte da população atendida ambulatorialmente e em sua rotina encaminhada à cirurgia eletiva. Por se tratar de grupo pequeno, foi mantido como parte do GE. Em todas as amostras de tumor desses pacientes foi detectado o DNA do HHV1, sem correspondência obrigatória no tecido sem lesão.

\section{DISCUSSÃO}

A infecção pelo HHV1 é das mais prevalentes na população. Essa infecção é recorrente, e caracteriza-se por apresentar períodos de latência. Pode ocorrer em qualquer parte do tegumento, mas é descrita predominantemente em áreas fotoexpostas. In vitro, alguns ensaios mostram que esse vírus pode determinar modificações genéticas e levar ao câncer. ${ }^{18,19}$

TABela 1: Distribuição da presença do HHV1 + na pele não tumoral dos dois grupos

\begin{tabular}{|c|c|c|c|c|c|}
\hline & \multicolumn{2}{|c|}{$\begin{array}{l}\text { Grupo de estudo } \\
\text { (pele normal) }\end{array}$} & \multicolumn{2}{|c|}{ Grupo controle } & \multirow[t]{2}{*}{ Tota } \\
\hline & $\mathbf{N}$. & $\%$ & & $\%$ & \\
\hline HHV1+ & 10 & 24 & 20 & 49 & 30 \\
\hline HHV1- & 31 & 76 & 21 & 51 & 52 \\
\hline Total & 41 & & 41 & & 82 \\
\hline
\end{tabular}

Teste de Fisher: $\mathrm{p}=0,038$ 
TABela 2: Distribuição da presença do HHV1+ no tumor, em relação ao controle de pele sem lesão, no mesmo grupo

\begin{tabular}{llllll}
\hline $\begin{array}{l}\text { Controle } \\
\text { (pele sem lesão de portador de neoplasia cutânea) } \\
\text { Tumor cutâneo }\end{array}$ & HHV1+ & HHV1- & Total \\
\hline & N. & $\%$ & N. & $\%$ & \\
\cline { 2 - 6 } & 6 & 60 & 11 & 35 & 17 \\
HHV1+ & 4 & 40 & 20 & 65 & 24 \\
\hline Total & $\mathbf{1 0}$ & $\mathbf{3 1}$ & $\mathbf{4 1}$ \\
\hline
\end{tabular}

Teste de McNemar exato: $\mathrm{p}$-valor $=0.1185$

Em relação à oncogenia viral, de maneira geral, muito já se sabe sobre a participação de alguns vírus na carcinogênese, tendo sido demonstrada sua presença em uma série de neoplasias. Algumas delas podem ser representadas pelos carcinomas de trato geniturinário, linfomas, neoplasias orais. Entre os tumores cutâneos, os mais intimamente relacionados à infecção viral, na literatura, são o sarcoma de Kaposi e aqueles relacionados a doenças genéticas, como xeroderma pigmentoso e $\mathrm{EV}^{20-21}$

Não existe confirmação experimental de oncogenia do HHV1 na pele, ainda que existam evidências de transformação viral pela radiação ultravioleta. ${ }^{22,23}$

Paralelamente, as neoplasias cutâneas epiteliais, como o CEC, o CBC e as QA, também são mais frequentes nas áreas expostas ao sol. Sabe-se que a radiação ultravioleta pode afetar o DNA, e esse erro pode escapar dos mecanismos de reparo, permitindo o desenvolvimento de câncer cutâneo. Além disso, existem alguns genes, como o que codifica a proteína $\mathrm{p} 53$ e gene patched, marcadores importantes da indução de neoplasia pela radiação ultravioleta, que podem sofrer mutações. ${ }^{24}$

Diante de amostra representativa, a fim de comparação, foi necessário utilizar parâmetro semelhante entre os grupos de estudo e controle; no caso, as amostras de pele normal. Dessa forma, pôde-se demonstrar neste estudo a presença significativa do HHV1 na pele sã de indivíduos não portadores de neoplasias cutâneas, quando comparada à pele sã daqueles com neoplasias.

Por outro lado, entre os 21 pacientes do grupo de estudo que expressaram o HHV1 em alguma das amostras coletadas, estes o fizeram em sua maioria (17) no tecido tumoral, sendo 11 deles com exclusividade nesse local.

Diante desse fato, não há como saber se o agrupamento viral facilitaria o desenvolvimento da neoplasia ou haveria coincidência de o HHV 1 localizar-se justamente onde já ocorreu transformação neoplásica. Sendo assim, parece não haver necessariamente relação direta entre o encontro do DNA do HHV 1 na pele sã e na pele tumoral.

A distribuição dos padrões histológicos dos tumores identificados neste estudo se fez de tal forma, que os tumores de linhagem espinhosa (CEC e QA) expressaram mais frequentemente o HHV 1, quando comparados ao CBC. Ainda que o CEC não seja o mais prevalente no Brasil, seu predomínio no presente estudo talvez se explique pelo fato de o grupo estudado ter-se formado por pacientes com lesões maiores, submetidos à cirurgia, que pudessem fornecer material suficiente para a pesquisa sem prejuízo para o diagnóstico e tratamento. Esse grupo coincide basicamente com o formado por CEC.

Observaram-se ainda dois fatos, não confirmados estatisticamente, mas considerados de relevância clínica.

Nos tumores dos pacientes HHV1-positivos pôde-se evidenciar padrão marcantemente mais agressivo, do ponto de vista clínico. Ainda que o procedimento não estivesse previsto na metodologia, ao revisar-se o prontuário desses pacientes, verificou-se histórico de tumores múltiplos, com alto índice de recorrência, resistência ao tratamento e que demandavam hospitalização. Esses dados não foram analisados estatisticamente.

Claudy e col. identificaram o HHV1 em células de um CEC clinicamente agressivo, recidivante e de difícil manejo. ${ }^{25}$ Estudos posteriores podem vir a confirmar essa afirmação e até correlacioná-la à presença do vírus na pele.

Pôde-se ainda observar num pequeno grupo de pacientes submetidos a transplante renal o DNA do HHV1 nas biópsias de tumor, mas não na pele não acometida pela neoplasia.

É conhecido o fato de a imunossupressão quimicamente induzida facilitar o surgimento de infec- 
ções virais. Depois de seis meses do transplante, a maioria desses indivíduos desenvolve alguma virose, especialmente HHV1, cursando com mudanças no perfil sorológico. ${ }^{26}$

Esse grupo de transplantados renais é conhecido por apresentar alta incidência de neoplasias cutâneas, o que se justifica pela diminuição dos mecanismos de imunovigilância, induzidos pela supressão química. ${ }^{27,28}$

Em estudo recente, Wilkins et al. descrevem as múltiplas relações entre neoplasias cutâneas malignas e doença pelo vírus da imunodeficiência humana, reforçando as relações entre vírus, câncer e imunossupressão. Os autores afirmam que a presença do vírus é necessária, mas não suficiente, para causar a neoplasia. De maneira que o surgimento do mecanismo deve envolver ainda susceptibilidade genética ou exposição ambiental. ${ }^{29}$

\section{CONCLUSÃO}

O HHV1 foi identificado em alta prevalência nos dois grupos estudados.

Ainda que não tenha sido identificada relação direta de causalidade entre a presença do HHV1 na pele aparentemente sã e o desenvolvimento da neoplasia cutânea epitelial maligna, deve-se considerar uma possível participação desse vírus, num contexto multifatorial, na oncogênese cutânea.

\section{REFERÊNCIAS}

1. Biliris KA, Koumantakis E, Dokianakis DN, Sourvinos $G$, Spandidos DA. Human papillomavirus infection of non-melanoma skin cancers in immunocompetent hosts. Cancer Lett. 2000;161:83-8.

2. Butel JS. Viral carcinogenesis: revelation of molecular mechanisms and etiology of human disease.

Carcinogenesis. 2000;21:405-26.

3. Chan PK, Chan MY, Li WW, Chan DP, Cheung JL, Cheng AF. Association of human herpesviruses with the development of cervical cancer: by standers or cofactors. J Clin Pathol. 2001;54:48-53.

4. Rady PL, Yen A, Rollefson JL, Orengo I, Bruce S, Hughes TK, et al. Herpesvirus - like DNA sequences in non-Kaposi's sarcoma skin lesions of transplant patients. Lancet. 1995;345:1339-40.

5. Orth G. Epidermodysplasia verruciformis: a model for understanding the oncogenicity of human papillomaviruses. Ciba Found Symp. 1986;120:157-74.

6. Rapp F, Reed CL. The Viral Etiology of cancer. Cancer. 1977;40:419-29.

7. Yuspa SH. The pathogenesis of squamous cell cancer: lessons from studies of skin carcinogenesis. J Dermatol Sci. 1998; 17:1-7.

8. Meyer T, Arndt R, Christophers E, Stockfleth E. Frequency and spectrum of HPV types detected in cutaneous squamous-cell carcinomas depend on the HPV detection system: a comparison of four PCR assays. Dermatology. 2000;201:204-11.

9. Majewski S, Jablonska S. Human papillomavirus-associated

tumors of the skin and mucosa. J Am Acad Dermatol. 1997;36:659-85.

10. Majewski S, Jablonska S. Do epidermodysplasia verruciformis human papillomaviruses contribute to malignant and benign epidermal proliferation? Arch Dermatol. 2002;138:649-54.

11. Vousden KH, Farrel PJ. Viruses and human cancer. Br Med Bull. 1994;50:560-81.

12. Zafiropoulos A, Tsentelierou E, Billiri K, Spandidos DA. Human herpes viruses in non-melanoma skin cancers. Cancer Lett. 2003;198:77-81.

13. Niedobitek G, Meru N, Delecluse HJ. Epstein-Barr vírus infection and human malignancies. Int $J$ Exp Path. 2001;82:149-70.

14. Nishimoto $\mathrm{S}$, Inagi $\mathrm{R}$, Yamanishi $\mathrm{K}$, Hosokawa $\mathrm{K}$, Kakibuchi M, Yoshikawa K. Prevalence of human herpesvirus 8 in skin lesions. Br J Dermatol. 1997; 137:179-84.

15. Nagore E, Ledesma E, Collado C, Oliver V, Perez-Perez A, Aliaga A. Detection of Esptein-Barr vírus and human herpesvirus 7 and 8 genomes in primary cutaneous T- and B-cell lymphomas. Br J Dermatol. 2000;143:320-3.

16. Mitchell OS, Espy MJ, Smith TF. Laboratory diagnosis of central nervous system infection with herpes simplex virus by PCR performed with cerebrospinal fluid specimens. J Clin Microbiol. 1997;35:2873-77.

17. Fleiss JL. Statistical Methods for rates and proprotions. 2nd ed. Nova Iorque: John Wiley and sons Inc; 1981. p. 38-46.

18. Abrahams PJ, van der Kleij AA, Schouten $\mathrm{R}$, van der Eb 
AJ. Absence of induction of enhanced reactivation of herpes simplex virus in cells from xeroderma pigmentosum patients without cancer. Cancer Res. 1998;48:6054-7.

19. Hollinshead AC, Chretien PB, Lee OB, Tarpley JL, Kerney SE, Silverman NA. In vivo and in vitro measurements of the relationship of human squamous carcinomas to herpes simplex virus associated antigens. Cancer Res. 1976;36:821-8.

20. Geraminejad P, Memar O, Arason I, Rady PL, Hengge U, Tyring SK. Kaposi's sarcoma and other manifestation of human herpesvirus 8. J Am Acad Dermatol. 2002; 47:641-5.

21. Dreno B, Clerier P, Fleischmann M, Bureau B, Litoux P. Presence of Epstein-Barr virus in cutaneous lesions of mycosis fungoides and Sezary syndrome. Acta Derm Venereol. 1994;74:355-7.

22. Stock C, Guillen-Grima F, de Mendoza JH, MarinFernandez B, Aguinaga-Ontoso I, Kramer A. Risk factors of herpes simplex type 1 (HSV-1) infection and lifestyle factors associated with HSV-1 manifestations. Eur J Epidemiol. 2001;17:885-90.

23. Darai G, Munk K. Neoplastic transformation of rat embryo cells with Herpes Simplex Virus. Int J Cancer. 1976;18:469-81.

24. Lacour JP. Carcinogenesis of basal cell carcinomas: genetics and molecular mechanisms. Br J Dermatol. 2002;146(Suppl 61):S17-9.

25. Claudy AL, Chignol MC, Chardonet Y. Detection of herpes simplex virus DNA in a cutaneous squamous cell carcinoma by in situ hybridization. Arch Dermatol Res. 1989; 281:333-5.
26. Matas AJ, Simmons RL, Najarian JS. Chronic Antigenic stimulation, herpesvirus infection and cancer in tranpalt recipients. Lancet. 1975;7:1277-9.

27. Jong-Tieben LM, Berkhout RJM, Schegget JT, Vermeer BJ, de Fijter JW, Bruijn JW, et al. The prevalence of human papillomavirus DNA in benign keratotic skin lesions of renal transplant recipients with and without history of skin cancer is wqually high: a clinical study to assess risk factors for keratotic skin lesions and skin cancer. Transplantation. 2000;69:44-9.

28. Hofbauer GFL, Dummer R, Hafner J, Burg G, Binswanger $U$, Kempf $W$. Skin cancer in organ transplant recipients: two cases of virus-induced neoplasms. Dermatology. 2001;202:359-61.

29. Wilkins K, Turner R, Dolev JC, LeBoit PE, Berger TG, Maurer TA. Cutaneous malignancy and human immuno deficiency virus disease. J Am Acad Dermatol. 2006;54:189-206.

Como citar este artigo/How to cite this article: Ypiranga S, Moraes AM. Prevalência do herpes-vírus humano tipo 1 em neoplasias cutâneas epiteliais malignas. An Bras Dermatol. 2009;84(2):137-42. 